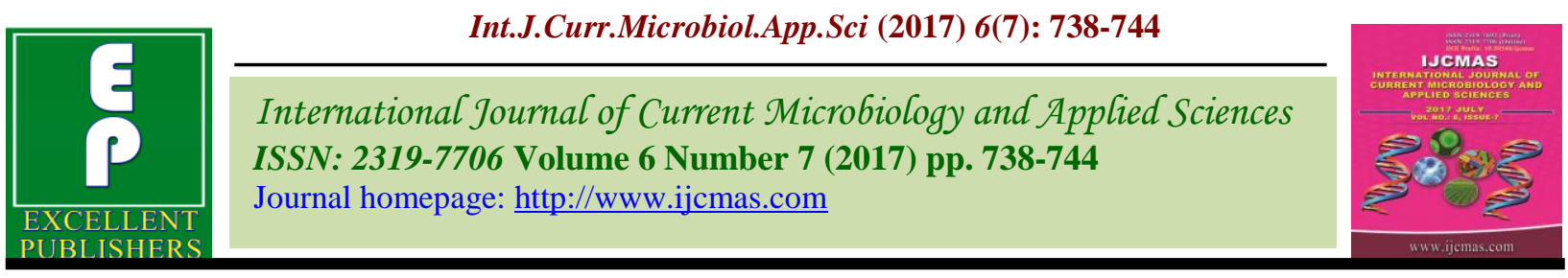

Original Research Article

https://doi.org/10.20546/ijcmas.2017.607.092

\title{
DEXCEL Map - A New Approach to Prepare Soil Fertility Map
}

\author{
G.R. Rajakumar ${ }^{1}$ and S.V. Patil ${ }^{2 *}$ \\ ${ }^{1}$ Department of Soil Science, Department of NRM, College of Forestry, Sirsi, \\ Uttar Kannada district, University of Agricultural Sciences, Dharwad, Karnataka, India \\ ${ }^{2}$ Department of Agronomy, Regional Horticultural Research and Extension Center, UHS \\ campus, GKVK, Bengaluru 65, Karnataka, India \\ *Corresponding author
}

\section{Keywords \\ Soil Fertility Map, Excel-free form- shapes-polygon, DEXCEL map, Soil properties. \\ Article Info \\ Accepted: \\ 14 June 2017 \\ Available Online: \\ 10 July 2017}

\section{A B S T R A C T}

Usually soil fertility maps are prepared by software such as Erdas/ArcGIS. These softwares are available with high price. Non-technical persons cannot use these for the preparation of the maps of their villages and interested areas. It is possible to prepare soil fertility maps by use of MS office (word / Excel / power point). The methodology has been explained to create the maps using village land map with survey numbers in excel sheet. It is possible to create-excel-freeform-shapes-from-polygons on any map. A base map has been prepared in excel sheet for DEXCEL map by placing a polygon on each plot (with survey number). An exercise of defining row height and column width in the excel sheet is required for the map preparation. The village Itagi is a part of Ranebennur taluk, Karntaka, India which has major soil types Black Clay soil and Red Sandy loam soil. Problem cause analysis indicated the low soil fertility status and unscientific use of fertilizers as the reasons for low crop yields. This has necessitated the preparation of soil fertility map of the village as a whole. The ground Co-ordinates of village map are gained from Google map for the village. In 86 random locations (on selected survey numbers) soils are sampled, labeled and processed. Samples are analyzed for Soil pH, Electrical Conductivity (EC), Organic Carbon, macro nutrients and micro nutrients. The status of soil for each property is classified into three classes. Looking to each survey number on the excel sheet, the polygons are filled with colours for respective classes (low, medium and high). The results revealed that 69 percent of samples belong to alkaline $\mathrm{pH}$ and oil salinity is medium in the area. Available nitrogen and phosphorous are low (59\% and $48 \%$ ) and Available potash is medium ( $70 \%$ ). Organic $\mathrm{C}$ belongs to medium to low category. B belongs to low category, while majority of the soils have low status of other micronutrients except $\mathrm{Cu}$. The DEXCEL maps prepared for $\mathrm{pH}$, Av.NPK and Organic $\mathrm{C}$ indicate the status of soil properties in the village land on respective survey numbers. Which side of the village, the particular soil parameter belongs to low category can be observed and suitable measure can be adopted for the management.

\section{Introduction}

In the digital era, soil maps come in various digital vector and raster formats and are used for various applications in geosciences and environmental sciences. Among them, Soil fertility map is one which is a geographical representation showing diversity of soil properties (soil pH, EC, Organic Carbon, Available nutrients, etc.) in the area of interest. To prepare such soil fertility maps, the sophisticated software such as Erdas / 
ArcGIS v 10 (Antharyami et al., 2014; Prabhavathi et al., 2015; Dhayalan et al., 2016) are used for geo-referencing. The georeferenced map will be digitized by creating personal geo-database and feature classes (point, line, and polygon). The map digitized will be projected for accurate information. These softwares are very expensive. Only few technical persons those have the knowledge of GIS software are able to prepare the soil fertility maps. So, in-order to prepare these maps can we use any ordinary method? It should be prepared by a person who knows only MS Office (word/excel/power point). In this context, the article aims at preparation of soil fertility maps by anyone including nontechnical and educated rural youths without the costlier software.

\section{What is DEXCEL map?}

It is Dharwad's excel format soil fertility map. Believe it or not! You can prepare the maps by using excel sheet. It is possible to create-excel-freeform-shapes-from-polygons on any maps (Anonymous, 2015).

\section{The study area}

The village selected is Itagi (Fig. 1). It is located in the Southern part of Ranebennur taluk, Karntaka, India which falls in between north latitudes $14^{\circ} 33.75^{\prime}$ and $14^{\circ} 31.50^{\prime}$ and east longitudes $75^{\circ} 39^{\prime}$ and $75^{\circ} 42^{\prime}$. The major soil types in this village are Black Clay soil (towards south west) and Red Sandy loam soil (towards north east). Climate of the area is with average maximum temperature of about $38^{\circ} \mathrm{C}$ in April and average minimum temperature of about $20^{\circ} \mathrm{C}$ in December. The Normal rainfall is about $560 \mathrm{~mm}$. The crops grown are Maize, Cotton, Jowar, Groundnut, Onion, Garlic, Bengal gram, Soybean, Banana, Chilli, and Tomato. Average crop yields are low to medium. Problem cause analysis indicated the soil fertility status and unscientific use of fertilizers as the reasons. This has necessitated the preparation of soil fertility map of the village as a whole.

\section{Materials and Methods}

To prepare Dexcel map, it is required to have the village land map (with survey numbers and boundaries), Camera / Camera phone / scanner and Computer with internet. The map of the village (survey numbers and boundaries) is obtained from the village accountant / field officer of Tahsil (taluk) office. The JPEG photo of map has been obtained through camera phone. If map is too big, part by part can be joined to get as one photo using power point.

The ground Co-ordinates of village map are gained from Google map for the village looking into the map shape and real colour image on the Google earth (Anonymous, 2017). It is easy to cut the area and select for saving it as a photo. The layout of the map is prepared with latitude and longitude for better understanding and more informative.

The soil samples are collected from each plot (for selected survey numbers) in zig-zag paths by using a spade by digging a $\mathrm{V}$-shaped hole to sample depth $0-20 \mathrm{~cm}$ and then a thin slice of soil is taken from one side of the pit. The samples collected from every pit are mixed, reduced to about half-a-kg and labeled as sample no.1. In similar manner 86 random locations (on selected survey numbers) are sampled and labeled. Then the soil samples are dried and sieved in order to remove other particles. Samples were analyzed for Soil $\mathrm{pH}$, Electrical Conductivity (EC), Organic Carbon, macro nutrients and micro nutrients by using the standard procedures (Jackson, 2012). The status of soil for each property is classified into three classes. The soil $\mathrm{pH}$ is classified into Acidic (<6.5), Neutral (6.5-7.5) and Alkaline (>7.5); the EC of soil is divided 
into low $(0.4 \mathrm{dS} / \mathrm{m})$, medium (0.4-4.0) and saline (>4.0). The Organic Carbon and available nutrients have been grouped into low, medium and high classes.

\section{Preparation of base map for DEXCEL map}

If you open an excel sheet in a computer, it is known that sheet 1 , sheet 2 and sheet 3 will appear with a window on the screen. You can delete sheets and add also as required. A base map is required for DEXCEL map which can be prepared by using JPEG photo of the village. Since photos are with 1 to $2 \mathrm{MB}$ or more sized, those have to be reduced to small sized by pasting it on to a Power Point slide, squeeze the size diagonally nearly equal to slide size, then copy it and paste it to 'excel' sheet 1 . Drag the photo diagonally to fit in to window size. Do not squeeze to abnormal shape. It should look like the village map with survey boundaries (Fig. 2). Zoom the view to 300 percent. Then start inserting shapes on all boundary lines using free form line polygon:

Select 'Insert' - Select 'Shapes' - Select 'lines polygon'

First draw lines on complete border of the map by clicking at start point and at every bent position. On joining of start point and end point, a polygon will appear with colour filled inside (usually blue). This colour has to be vacated by clicking on the line polygon and by selecting the appeared option 'Format shape' then in 'Fill' menu 'No fill' has to be selected.

Then background map will appear with only border line. This exercise has to be done for all the survey number plots. Over-writing on previous line has to be done for adjacent plots so as to select an individual plot while preparing DEXCEL map. At the end of each polygon there is no need to remove the filled colour. At the end, on completion of marking of all the plots, the filled colour can be removed at a time:

Select 'Control A' - Click right mouse on any line polygon and select option 'Format object' and in Fill menu- 'No fill' has to be selected. Then background map will appear with only border lines along with background photo. Select Control A, keep holding control and de-select only the background photo; Copy and paste it to sheet 2 . Only with border lines the entire village with boundaries to each survey number will appear on the screen with background excel sheet's rows and columns. Now group all the borders. Select 'Control A' and click right mouse after keeping the cursor on any line polygon. Options will appear and select 'group'. All will be joined as one unit.

In sheet 3 , define the row height and column width (as $5 \times 2.81$ ). To define, click right mouse on right hand corner of the sheet. Entire sheet will be selected. Click right mouse on any row number and define row height as 5 and again click mouse on any column alphabet and define column width as 2.81 . Copy the grouped polygon from sheet 2 on to sheet 3 now. Define again the row height and column width (as $15 \times 8.43$ ). The map will also spread accordingly. Type the survey numbers in each representative cell of the excel sheet (font size: 4) which is at the background of the map. Try to match the cell placement and centre of the plot by aligning so that the survey number is clearly visible. After indicating all the survey numbers, show the village with filled texture pattern. Again define the row height and column width (as $5 \times 2.81$ ) to fit in to original size. Now the map is ready to use as the base map for DEXCEL map.

\section{Preparation of DEXCEL map}

Base map has been used to prepare the DEXCEL map. The sheet 3 is copied into several sheets for each soil property. Sheet 3 
should not be used for colouring but the copies made out of it can be used. Keep sheet three as a reserve. As per the soil status, the colour has been filled into each plot with survey number boundary. Low category plots are selected by pressing control and clicking mouse on the line of polygon and the colour is filled (red). Individual plots may be coloured or few together can be selected by using 'Control button' and select the polygon. Similarly medium category plots and high category plots are also selected and the colours are filled (yellow and green).

The soil $\mathrm{pH}$ has been indicated with red, green and blue colours for acidic, neutral and alkaline categories. The EC classes have been indicated with Yellow, green and red for low, medium and saline categories. Organic C, major and micro nutrients classes have been given with red, yellow and green for low, medium and high status of soil. At the top the title of the soil fertility map of the village should appear (merge three to four lines from on the top left side to right side of the photo for typing title; font size : 18). And at the bottom index is given for different classes (font size: 16). If possible, class values may be indicated at any leftover outside place (font size: 8 ) in the map otherwise indicate along with the index.

Now, the DEXCEL map is ready for interpretation. The analytical data is used for knowing the status of soil properties of village as a whole. And the map is used for interpreting which side of the village is having critical nutrient status and other soil properties for efficient management plans. In order to take the printout as photo it is necessary to take only map image (without survey number); select 'only map image', copy and paste on to power point slide.

Add the title and index details again here on to power point slide. Select all by 'Control A', click mouse on polygon and select 'group or regroup'. Then again select all by 'Control A', click mouse on polygon and select 'Save as picture'; give file name and save in JPEG format. This can be as a DEXCEL map.

\section{Results and Discussion}

The results of soil analysis, as indicated in the table 1, revealed that 69 percent of samples belong to alkaline $\mathrm{pH}$ and 28 percent of the samples belong to neutral range of $\mathrm{pH}$ of soils. However the soil salinity is medium in the area. Available nitrogen is low (59\%) and medium $(30 \%)$. Available phosphorous is low (48 \%) and medium (44\%). Available potash is low (15\%) and medium (70 \%). Fifty eight percent of the samples for organic $\mathrm{C}$ belong to medium category and forty percent of the samples for organic $\mathrm{C}$ belong to low category. All the samples for available B belong to low category. While majority of the soils have low status of other micronutrients except $\mathrm{Cu}$.

The following DEXCEL maps prepared for $\mathrm{pH}, \mathrm{Av}$. NPK and Organic C indicate the status of soil properties in the village land on respective survey numbers. Which side of the village, the particular soil parameter belongs to low category can be observed and suitable measure can be adopted for the management.

These results indicate that there is a need of complete management of soils for the improvement of their properties. The gypsum needs to be applied to reduce the $\mathrm{pH}$ (Giovanna et al., 2012). Available nitrogen has to be increased through organic means as the soils are completely fall under low category of organic $\mathrm{C}$ besides application of $25 \%$ more quantity than RDF. Soils having low status of $\mathrm{P}$ and $\mathrm{K}$ also needs applied with $25 \%$ more quantity than RDF. Wherever the micro nutrients are deficient, there is a need of application to the extent of $10 \mathrm{~kg} / \mathrm{ha}$ or as recommended dosage. 
Fig.1 Itagi village, Ranebennuru Taluk, Haveri District

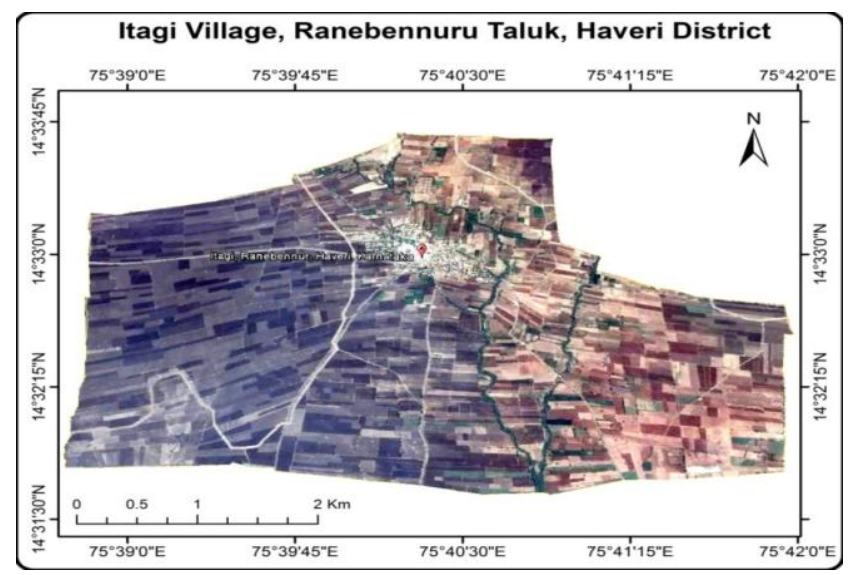

Fig.2 Itagi village map with boundary lines to each survey number
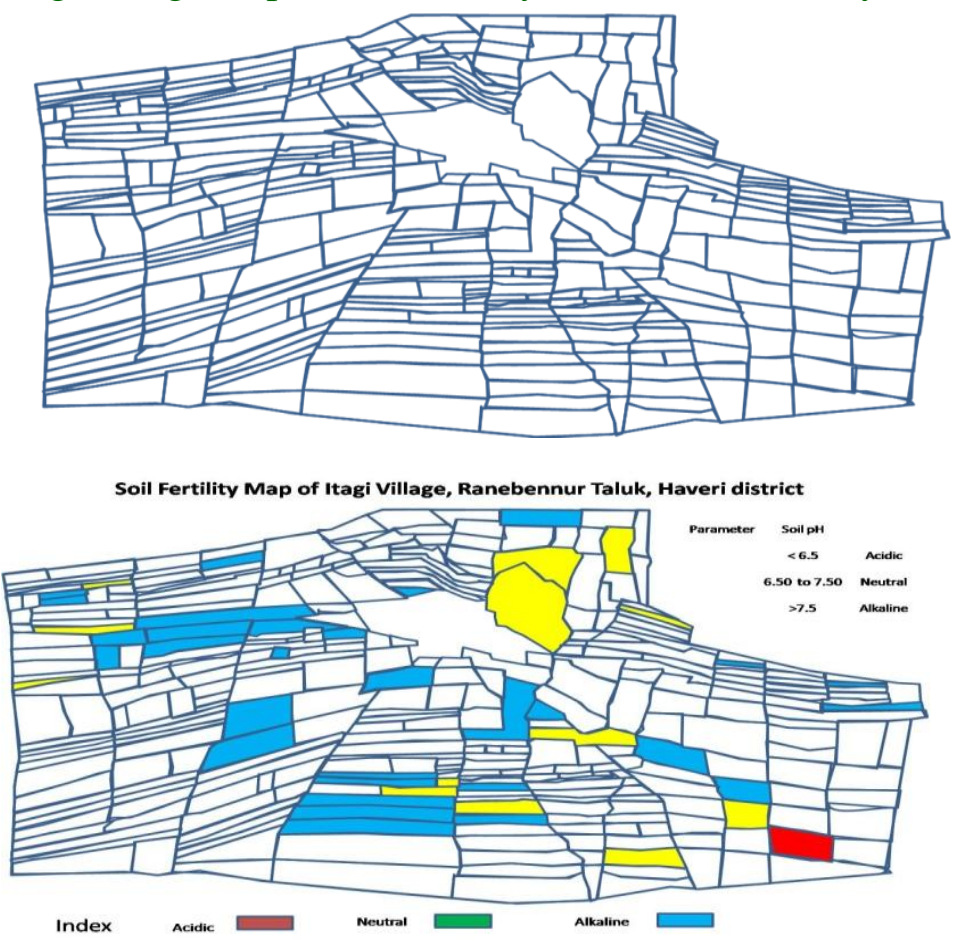

Soil Fertility Map of Itagi Village, Ranebennur Taluk, Haveri district

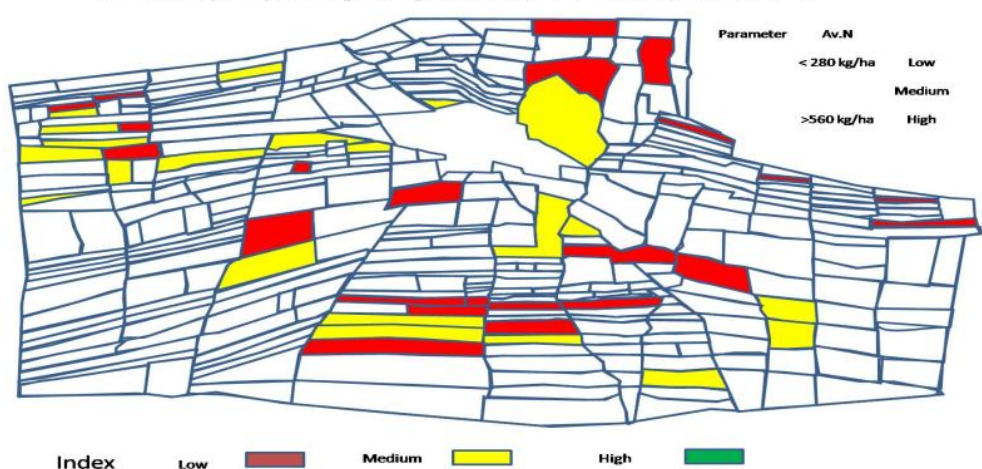



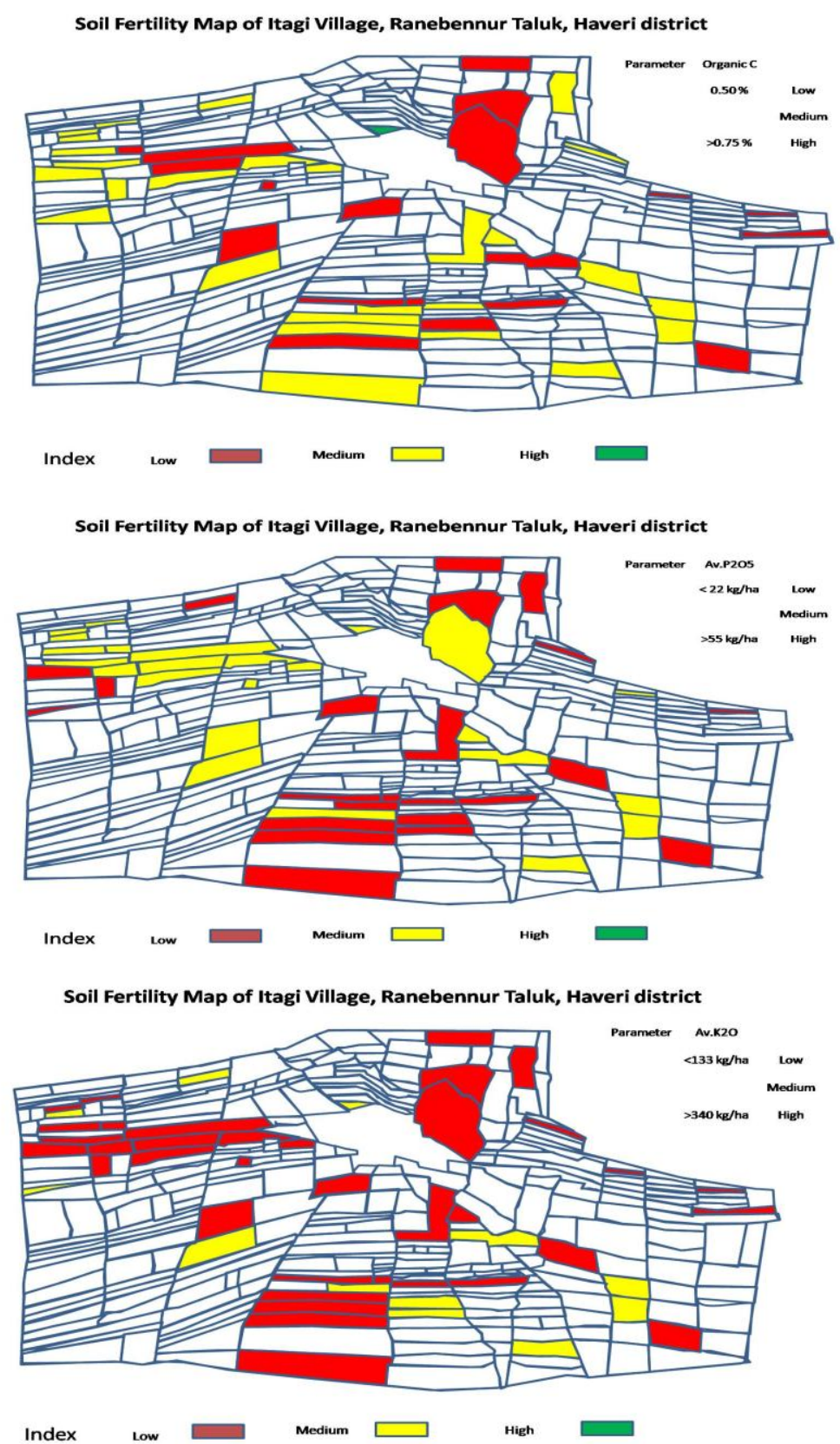

Table.1 Number of soils belonging to different classes of soil properties in Itagi village

\begin{tabular}{|c|c|c|c|c|c|c|c|c|c|c|c|c|}
\hline Class & $\begin{array}{c}\text { Soil } \\
\text { pH }\end{array}$ & EC & Av. $\mathbf{N}$ & $\begin{array}{c}\text { Av. } \\
\mathbf{P}_{2} \mathbf{O}_{\mathbf{5}}\end{array}$ & $\begin{array}{c}\text { Av. } \\
\mathbf{K}_{\mathbf{2}} \mathbf{O}\end{array}$ & $\begin{array}{c}\text { Av. } \\
\text { S }\end{array}$ & Org.C & Av. B & $\begin{array}{c}\text { Av. } \\
\mathbf{Z n}\end{array}$ & $\begin{array}{c}\text { Av. } \\
\text { Mn }\end{array}$ & $\begin{array}{c}\text { Av. } \\
\text { Fe }\end{array}$ & $\begin{array}{c}\text { Av. } \\
\text { Cu }\end{array}$ \\
\hline Low & 3 & 1 & $\begin{array}{c}59 \\
(69)\end{array}$ & $\begin{array}{c}48 \\
(56)\end{array}$ & $\begin{array}{c}15 \\
(17)\end{array}$ & 34 & 86 & 56 & 72 & 71 & 82 & 0 \\
$(100)$ & $(65)$ & $(84)$ & $(83)$ & $(95)$ & \\
\hline Med & $\begin{array}{c}24 \\
(28)\end{array}$ & $\begin{array}{c}82 \\
(95)\end{array}$ & $\begin{array}{c}26 \\
(30)\end{array}$ & $\begin{array}{c}38 \\
(44)\end{array}$ & $\begin{array}{c}60 \\
(70)\end{array}$ & $\begin{array}{c}50 \\
(58)\end{array}$ & 0 & 30 & 14 & 15 & 3 & 86 \\
$(35)$ & $(16)$ & $(17)$ & $(4)$ & $(100)$ \\
\hline High & $\begin{array}{c}59 \\
(69)\end{array}$ & 3 & 1 & 0 & 11 & 2 & 0 & 0 & 0 & 0 & 1 & 0 \\
\hline
\end{tabular}

*values in parenthesis indicate the percent of samples 
Similar to these maps any other map can be prepared and if all the samples from all the survey numbers are drawn and analysed for the soil properties, all the plots can be seen with colours.

In conclusion, the preparation of soil fertility maps using GIS is not affordable to everybody and the softwares are high priced. Moreover these can be handled only by the trained experts.

So, In order to have village soil fertility map even by fertilizer dealer an easy and MS office based (word. Excel. Power point), particularly excel sheet based DEXCEL map has been developed (Anonymous, 2008). Anybody interested can look into the procedure, open an excel sheet and practice for preparation of soil fertility map of the interested area.

\section{References}

Anonymous, 2008, How to create a thematic map in Excel, https://excelcharts.com/how-to-createthematic-map-excel/

Anonymous, 2015, Create-excel-freeformshapes-from-polygons. http://www. clearlyandsimply.com/clearly_and_simp ly/2015/04/create-excel-freeformshapes-from-polygons.html

Anonymous, 2017, Village Maps of India, http://villagemap.in/

Antaryami Mishra, Truptimayee Pattnaik, D. Das and Mira Das, 2014, Soil Fertility Maps Preparation Using GPS and GIS in Dhenkanal District, Odisha, India, International Journal of Plant \& Soil Science,: 3(8): 986-994

Dhayalan.V, Muthu Selvam.M, Ramaraj. M, 2016, International Journal of Engineering Research and General Science, $4: 218-230$

Giovanna Cucci, Giovanni Lacolla, Mauro Pallara and Rocco Laviano, 2012, Reclamation of saline and saline-sodic soils using gypsum and leaching water. African Journal of Agricultural Research Vol. 7(48), pp. 6508-6514

Jackson, M.L., 2012, Soil Chemical Analysis. Publisher, Prentice-Hall, Inc.,

Prabhavati, K and Dasog, G S and Patil, P L and Sahrawat, K L and Wani, S P, 2015, Soil Fertility Mapping using GIS in Three Agro-climatic Zones of Belgaum District, Karnataka. Journal of the Indian Society of Soil Science, 63 (2):173-180.

\section{How to cite this article:}

Rajakumar, G.R. and Patil, S.V. 2017. DEXCEL Map - A New Approach to Prepare Soil Fertility Map. Int.J.Curr.Microbiol.App.Sci. 6(7): 738-744.

doi: https://doi.org/10.20546/ijcmas.2017.607.092 